\title{
A construção de significados do infográfico "Panorama das favelas em Fortaleza” à luz da Gramática do Design Visual
}

\section{The construal meanings from the infografic "Panorama das favelas em Fortaleza" based on the Grammar of Visual Design}

\author{
Maria Aurea Albuquerque Sousa* \\ *Universidade Estadual do Ceará (UECE), Fortaleza, Ceará / Brasil \\ aureaalbu@gmail.com \\ http:/ / orcid.org/0000-0002-6995-4051
Michelle Soares Pinheiro** **Universidade Estadual do Ceará (UECE), Fortaleza, Ceará / Brasil michelle040481@hotmail.com https://orcid.org/0000-0001-8499-6658

\begin{abstract}
RESUMO: Neste artigo, analisamos o infográfico "Panorama das favelas em Fortaleza" com base na Gramática do Design Visual - GDV (KRESS; VAN LEEUWEN, 2006) e pelos conceitos teóricos da semiótica social (HODGE; KRESS, 1988), multimodalidade (KRESS; VAN LEEUWEN, 2001, 2002, 2006) e letramento multimodal crítico (CALLOW, 2008, 2012 2013; PAIVA, 2011; PINHEIRO, 2016; PREDEBOM, 2015; RIBEIRO, 2016; WALSH, 2010). Ao utilizarmos as metafunções da GDV, percebemos que o infográfico se apoia fortemente nos elementos imagéticos como representações conceituais, utiliza bastante as cores a fim de amenizar o estigma negativo da favela e apresenta dados estatísticos de uma pesquisa divulgada no ano de 2015. O infográfico analisado pode ser utilizado em sala de aula para desenvolver práticas de leitura multimodal crítica com estudantes.
\end{abstract}

PALAVRAS-CHAVE: Gramática do Design Visual; letramento multimodal crítico; infográfico; favela.

ABSTRACT: In this paper, we analize the infographic "Panoramas das favelas em Fortaleza", grounded on Grammar of Visual Design - GVD (KRESS; VAN LEEUWEN, 2006), Social Semiotics, (HODGE; KRESS, 1988), Multimodality (KRESS; VAN LEEUWEN, 2001, 2002, 2006) and on Critical Multimodal 
Literacy theories (CALLOW, 2008, 2012, 2013; PAIVA, 2011; PINHEIRO, 2016; PREDEBOM, 2015; RIBEIRO, 2016; WALSH, 2010). When we analize the infographic in light of the metafunctions of GVD, we realized that it is effectively based on visual elements as conceptual representations and uses colors in order to soften the negative stigma of the 'favela', and it also presents statistical data collected from a survey carried out in 2015. The infographic can be used in learning contexts to develop students' critical multimodal reading.

KEYWORDS: Grammar of Visual Design; critical multimodal literacy; infographic; favela.

\section{Introdução}

$\mathrm{Na}$ sociedade contemporânea, no Brasil e no mundo, vivemos cercados por imagens nas mais variadas formas como nos outdoors, nas revistas, nos jornais impressos e digitais, nas mídias digitais, nas redes sociais da internet (principalmente no Facebook), nas conversas pelos aplicativos de mensagens como Whatsapp, entre outras. Esse fenômeno é chamado por Mirzoeff (2003) de Cultura Visual. No entanto, isso não subestima a importância dos elementos escritos, pois ainda há uma valoração do verbal sobre o imagético. Para o autor, os modos semióticos escritos e imagéticos se integram e tornam, em geral, o texto mais compreensível e acessível aos leitores.

Diante dessa realidade, este artigo parte de uma inquietação quando nos deparamos com uma grande quantidade, cada vez mais frequente, das composições multimodais denominadas de infográficos presentes tanto na mídia impressa quanto na virtual-digital, os quais possuem funções e características peculiares a fim de atrair a atenção dos leitores-olhantes. ${ }^{1}$ Os infográficos reúnem e integram imagem e texto, num layout único que os diferencia de qualquer outra composição multimodal. A própria terminologia "infográfico" parece ser uma junção de informação com gráfico (info+graphic), o que nos sugere pela própria acepção do termo de que se trata de uma união de grandes quantidades de informação aliadas com a imagem.

Na perspectiva da semiótica social, entendemos os infográficos como composições complexas ou representações comunicacionais com alto grau

\footnotetext{
1 "Leitor-olhante" foi a nomenclatura adotada por Barbosa (2017) para se referir ao leitor que não só lê como olha e vê a imagem a fim de compreendê-la e de interagir com ela.
} 
de multimodalidade. Nesse sentido, neste artigo, propomo-nos a analisar o infográfico intitulado "Panorama das favelas em Fortaleza" com base na teoria da Gramática do Design Visual (GDV) de Kress e van Leeuwen (2006). Além disso, almejamos trazer uma reflexão para a necessidade latente de se desenvolver o letramento multimodal crítico a fim de "ler" e "ver" textos multimodais de forma mais crítica em sala de aula com alunos e professores por meio de infográficos.

\section{Referencial teórico}

A teoria explorada, neste artigo, apoia-se nas seguintes categorias: semiótica social; multimodalidade; letramento multimodal crítico; GDV com suas metafunções e categorias analíticas; e infográfico. Inicialmente, a semiótica social é definida por Hodge e Kress (1988) como a ciência da vida dos signos na sociedade, surgindo como uma maneira de sistematizar os estudos comunicacionais com a finalidade de dar ênfase às estruturas e aos códigos. Existe, na semiótica social, uma complexa inter-relação entre sistema semiótico e prática social, principalmente devido ao fato de os falantes e os escritores (ou outros participantes) estarem ligados e interagirem em uma variedade de modos em contextos sociais concretos.

Em meio a essa diversidade de modos semióticos, a multimodalidade se constrói como um campo de estudos que se destina a explorar as formas de significação modernas, o que abrange todos os modos semióticos inerentes aos processos de representação e comunicação (KRESS; VAN LEEUWEN, 2001). Assim, para Kress et al. (2001), o fenômeno multimodal, em meio à semiótica social, engloba vários modos semióticos, tais como linguagem escrita, imagem, layout, música, gestos, fala, objetos em 3D, entre outros. Estes se relacionam, diretamente, com as modalidades sensoriais (visual, auditiva, tátil, olfativa, gustativa e cinética). Dessa forma, na orquestração de significados, cada modo leva aos leitores significados e sentidos específicos e usufrui de suas propriedades internas para aguçar ou realçar o recurso semiótico.

Já o termo "multiletramentos" surgiu da reflexão do New London Group (2006), ${ }^{2}$ cujos integrantes perceberam que a globalização e as novas

\footnotetext{
${ }^{2}$ O New London Group foi composto, no ano de 1996, por Courtney Cazden, Bill Cope, Jim Gee, Gunther Kress, Allan Luke, Mary Kalantzis, Norman Fairclough, Carmen Luke,
} 
tecnologias reconfiguravam a "paisagem" comunicacional, afetando as pesquisas educacionais e linguísticas. Nesse âmbito, para o referido grupo, o conceito de letramento deve ser ampliado para dar conta da multiplicidade de discursos, da diversidade dos contextos sociolinguísticos e culturais e da pluralidade de textos que circulam nas sociedades globalizadas, abrangendo as tecnologias de informação e multimídia. Por isso, adotamos aqui o conceito de letramento multimodal crítico como um conjunto de usos e práticas sociais que envolvem a leitura e a escrita multimodais, permeados por discursos e ideologias, que têm como consequência a possibilidade de empoderamento social e de uma postura crítica do sujeito diante do(s) texto(s) multimodal(is) de modo que ele exerça sua plena cidadania (CATTO, 2013; KRESS et al., 2001; PINHEIRO, 2016; PREDEBOM, 2015; WALSH, 2010). Ressaltamos ainda que, nesse conceito, uma habilidade comunicativa muito relevante e necessária é o "ver", conforme Barbosa (2017) e Callow (2012), pois essa habilidade possibilita que o leitor-olhante procure por intenções, desejos e propósitos do criador da imagem, assim como esse leitor analisa suas próprias respostas e interpretações.

O letramento multimodal crítico se baseia, principalmente, na GDV de Kress e van Leeuwen (2006), ${ }^{3}$ em razão de esta ser um dos mais usados aportes teóricos do letramento multimodal. Dessa forma, para os referidos autores, as imagens são entendidas como uma fonte de vários recursos de construção de significados por meio das metafunções representacional, interativa e composicional, sendo que: na representacional, ações, eventos e conceitos simbólicos representam a realidade na imagem; na interativa, as relações entre o leitor-olhante e a imagem são evidenciadas por meio do contato, da distância ou da afinidade social, da perspectiva ou do ponto de vista e da modalidade ou do valor de realidade; e na composicional, as escolhas de layout e as combinações entre os elementos da imagem tornam o texto coerente, analisando aspectos como o valor de informação, o enquadramento, a saliência e a modalidade.

Na metafunção representacional, Kress e Van Leeuwen (2006) classificam as imagens em narrativas ou conceituais. As primeiras constroem

Sara Michaels e Martin Nakata.

${ }^{3}$ Kress e van Leeuwen, ao criarem a Gramática de Design Visual, basearam-se na Gramática Sistêmico-Funcional de Halliday (1978), cujas metafunções são ideacional, interpessoal e textual. 
a experiência como um evento que ocorre em consonância com o espaço e o tempo, ou seja, mostram os participantes realizando ações ou envolvidos em acontecimentos. As representações narrativas são caracterizadas também pelas circunstâncias, que podem ser o cenário, o meio e o acompanhamento. As representações narrativas podem ser realizadas por processos, que se relacionam aos "vetores", os quais indicam ações, reações, pensamentos e falas. Existem quatro tipos de processos: os de ação, os de reação, os mentais e os verbais.

No processo de ação, existem dois tipos de relações: a transacional, que se constitui como uma ação que envolve, no mínimo, dois participantes e há um vetor que os conecta; e a não transacional, que ocorre quando a ação envolve apenas um participante e um vetor. Ainda nos processos de ação, os participantes representados na imagem podem ser classificados como ator (aquele que executa a ação) e meta (aquele que recebe a ação ou que se coloca como objeto da ação). Já nos processos de reação, Kress e van Leeuwen (2006) e Fernandes e Almeida (2008) expõem que coexistem um reator (aquele que observa) e um fenômeno (o objeto alvo da atenção e da observação). Nos processos mentais, temos indicações de balões de pensamento conectados a um participante humano ou personificado. Nesses processos, temos o experienciador e o fenômeno. Nos processos verbais, há um vetor formado por um balão de diálogo ou por um dispositivo convencional semelhante, que serve para conectar dois participantes, o dizente (aquele que diz algo) e o enunciado (o que é dito). Podemos encontrar os processos mentais e verbais em tirinhas e charges.

As representações conceituais têm a função de descrever e/ou classificar os participantes na imagem em relação às suas características individuais, ressaltando a identidade do participante representado, ou de atributos, traços e características compartilhados com outros participantes, que nos permitem percebê-los na condição de membros de um grupo ou segmento social. Segundo Nascimento, Bezerra e Heberle (2011), são características das representações conceituais: disposição dos participantes em taxonomias; exposição dos participantes em relação entre parte e totalidade; ausência de vetores; pouco ou nenhum detalhamento do plano de fundo. Nas representações conceituais, a GDV faz a seguinte classificação: processos classificatórios, analíticos ou simbólicos.

Os processos classificatórios enfatizam as características dos participantes como integrantes de um grupo de forma implícita ou explícita. 
Em geral, existem nos processos classificatórios um elemento subordinado e outro superordinado. Os processos analíticos representam os elementos da imagem em uma relação estrutural de parte/todo, sendo o todo como o portador e as partes como os atributos possessivos. Os processos analíticos podem ser ainda classificados como estruturados (está clara a relação parte/todo) ou desestruturados. Os processos simbólicos apresentam elementos na imagem com um valor extra, que em geral não são ou não eram intrínsecos à imagem.

Kress e van Leeuwen (2006) apontam que, na metafunção interativa, as imagens podem ser construídas de modo a estabelecerem interações entre o produtor e o leitor-olhante. Assim, quem produz o texto imagético o faz numa instância discursiva em que, na imagem, há uma relação de maior ou menor proximidade com o seu interlocutor-olhante. Kress e van Leeuwen (2006) indicam os seguintes aspectos a serem analisados nesta metafunção: o contato, a distância, a perspectiva e a modalidade.

O contato através do olhar que o participante representado dirige ao leitor-olhante (ou contato estabelecido entre ambos) ou ainda um gesto com sua mão (SILVA, 2016), indicando convite, sedução ou desafio, demanda (demand) uma ação do observador. Esse recurso é denominado, assim, de olhar de demanda. Pode ocorrer ainda um olhar não direto para o observador da imagem, um olhar voltado à outra direção ou objeto, de forma a convidar o leitor a "ver" outro ponto focal da imagem. Assim, há uma oferta de algo a ser visto (offer), por isso é chamado de olhar de oferta.

A distância é determinada pelo enquadramento da imagem ou a posição que o participante representado estabelece com o observador. Num plano aberto, há um distanciamento entre participante e observador, já num plano médio haverá uma moderação intencional da distância estabelecida. Dessa forma, no plano fechado, haverá maior proximidade entre os participantes. Para Silva (2016, p. 73) "de acordo com o nível de enquadramento, os participantes são representados como pessoas íntimas, como amigos de quem os observam, ou como mais distantes e estranhos".

A perspectiva está relacionada ao ângulo em que o participante representado se encontra na imagem em relação ao observador. Conforme Nascimento, Bezerra e Heberle (2011), há um maior envolvimento entre os participantes num ângulo frontal, um de frente para o outro. O contrário ocorre em ângulos oblíquos, estabelecendo um distanciamento. Já um ângulo vertical fomenta o ponto de vista do observador, se for um olhar para cima 
em direção ao participante representado, denota uma representação de poder ou superioridade daquele sobre o observador. Tomemos como exemplo as frequentes imagens de líderes de governo, olhando de um ponto de vista superior ou mais alto que o leitor. O inverso ocorre num ângulo em que a perspectiva do observador seja superior. De acordo com a teoria da GDV, há uma relação de poder entre os participantes no aspecto da perspectiva.

A modalidade, conforme Kress e van Leewen (2006), diz respeito ao valor de verdade da representação da imagem, construído por meio dos diversos mecanismos modalizadores do nível de realidade que a imagem representa. Tais mecanismos são realizados pelo uso da cor (saturação, diferenciação, modulação), contextualização (como o cenário é representado em profundidade ou da sua quase ausência na imagem), representação (grau de detalhes dos participantes representados ou abstração dos detalhes e foco no aspecto mais geral), iluminação (o papel da luz ou de sua ausência na imagem), brilho (ligado ao grau máximo de brilho da imagem até sua total ausência, indo para os tons escuros ou acinzentados). São esses recursos que modalizam a representação naturalística ou mais abstrata da realidade. Kress e van Leeuwen (2006, p. 163, tradução nossa) destacam que "a realização da modalidade em imagens é muito mais complexa e finamente graduada do que a realização da modalidade em linguagem". ${ }^{4}$

A terceira metafunção da GDV é a composicional que explora os arranjos entre os elementos que compõem a imagem. São os aspectos organizacionais, espaciais e suas possíveis conexões dentro da imagem, ou como eles se combinam e se ligam para significarem. De acordo com Kress e van Leeuwen (2006, p. 176, tradução nossa), a categoria de análise composicional é "a forma como os elementos representativos e interativos se relacionam um com o outro, a maneira como eles são integrados para produzir significado". ${ }^{5}$ Os autores da GDV apontam três possibilidades ligadas a essa função: valor da informação (information value), saliência (salience) e enquadramento (framing). $\mathrm{O}$ valor da informação indica a posição que o elemento se encontra. Dessa forma, do ponto de vista do leitor, se estiver à esquerda, trata-se de uma informação dada ou conhecida, enquanto, à

\footnotetext{
${ }^{4}$ No original: "the realization of modality in images is much more complex and finely graded than the realization of modality in language".

${ }^{5}$ A versão original é "the way in which the representational and interactive elements are made to relate to each other, the way they are integrated into a meaningful whole".
} 
direita, está a informação nova. Se o elemento estiver no topo será uma informação idealizada, e se estiver na base será uma informação real. Ou ainda, elementos no centro da imagem podem ser vistos como informação principal, quando aparecem na margem podem ser vistos e lidos como informações complementares. A presença dessas três possibilidades espaciais confluindo-se na imagem são denominadas de tríptica (triptych) pelos autores da GDV. Quanto ao aspecto da saliência, este diz respeito ao destaque ou não a um elemento visual em relação a outro por meio do tamanho, cor e plano com o objetivo de chamar atenção do leitor-olhante. Por último, aponta-se o enquadramento (framing), definido como a conexão ou desconexão entre os elementos da imagem. Um enquadramento fraco realiza-se por meio de elementos visíveis na ligação ou coesão entre eles na imagem. Num enquadramento forte, a ligação entre eles é invisível, muito mais sugerida ou implícita do que mostrada com elos visuais.

Para desenvolver o letramento multimodal crítico e as habilidades de "ler" e "ver", o Show me framework de Callow (2008) pode ser empregado por educadores a fim de fomentar práticas de letramento por meio das dimensões afetiva, composicional e crítica. Na primeira dimensão, Callow (2008) defende que imagens são signos de engajamento afetivo, em que podemos perceber e avaliar essa dimensão por meio de gestos e expressões faciais dos alunos no momento em que participam da atividade de leitura e de interpretação do texto multimodal, em especial em relação aos elementos imagéticos. A dimensão afetiva também envolve a interpretação pessoal, em que os leitores/observadores trazem suas próprias experiências e preferências para uma imagem (CALLOW, 2008). Essa dimensão pode ser trabalhada, em sala de aula, com perguntas como: "você consegue encontrar uma imagem de que você realmente gosta ou não gosta? Por quê?” (CALLOW, 2008, p. 620, tradução nossa). ${ }^{6}$ Por meio dessas e de outras perguntas, o professor pode pedir para o aluno observar as imagens, comentá-las de forma positiva ou negativa, olhar novamente imagens particulares e, por último, expor o aproveitamento da leitura/observação.

A dimensão composicional está diretamente relacionada aos preceitos da GDV. Por isso, o professor deve direcionar as atividades de leitura por meio de perguntas que giram em torno dos elementos da imagem. Inicialmente, o docente deve questionar os estudantes sobre o que está acontecendo na imagem; se esta apresenta algum tema, sentimento ou ideia; e como a

6"Can you find me a picture you really like or dislike? Why?" (CALLOW, 2008, p. 620). 
imagem apresenta isso (CALLOW, 2008). A partir disso, os alunos podem descrever e explicar ações e imagens simbólicas. Em seguida, o educador poderá indagar sobre como as pessoas ou outros participantes reagem na imagem, analisando o nível dos olhos dos personagens representados e se eles se dirigem ao leitor-olhante. Dessa forma, a dimensão composicional fomenta a análise cuidadosa da específica metalinguagem da imagem dentro do texto multimodal, abrangendo conceitos como: ações, símbolos, distância/proximidade, ângulos, olhar, cores, layout, saliência, linhas e vetores (CALLOW, 2008). Por meio desses questionamentos, o professor instiga os estudantes a identificarem a saliência, os vetores e o caminho que os olhos dos leitores percorrem ao longo da página do livro, mostrando para o aluno os aspectos composicionais das imagens e como elas são relevantes na construção de sentidos e significados sobre o texto multimodal.

A dimensão crítica, segundo Callow (2008), diz respeito à percepção de questões socioculturais como a inclusão e a exclusão de grupos sociais, no tocante ao gênero, à raça e à etnia, sendo intermediado pelo professor por meio de perguntas. Essa intervenção docente faz com que os leitoresolhantes expressem seu ponto de vista para criticar as escolhas feitas pelos ilustradores e pelos produtores dos textos multimodais, considerando as ideologias e os discursos que estão sendo representados em determinada imagem. Assim, os estudantes poderão identificar e avaliar os estereótipos sociais construídos no texto multimodal, em especial nas imagens. Ao nosso ver, a dimensão crítica é muito importante e deve ser desenvolvida desde as séries iniciais a fim de propiciar um empoderamento social e um protagonismo educacional para os(as) alunos(as). Esclarecemos que a análise das dimensões deve ocorrer de forma conjunta e integrada, a fim de proporcionar um eficaz caminho para o desenvolvimento do letramento multimodal crítico. Nesse sentido, a partir dos preceitos da GDV e do Show me framework de Callow (2008), é possível analisar de forma profunda o infográfico selecionado.

Nessa linha de raciocínio, para Assunção (2012), o infográfico é um texto multimodal que contém diagramação e/ou tipografia esteticamente "agradáveis", com o objetivo de passar uma maior legibilidade e uma redução de elementos textuais, por meio do uso de elementos gráficos e icônicos, oportunizando maior rapidez na leitura. Na ótica de Paiva (2011), o infográfico é considerado um gênero textual que integra modos semióticos de forma proporcional, a fim de explicar como funciona um objeto, como ocorrem fenômenos biofísico-químicos ou como é ou foi um fato geo- 
histórico, podendo circular nas esferas jornalística e didática e podendo se integrar a outros gêneros textuais com a finalidade de veiculação de discursos. Franchi (2010, p. 2) defende que os infográficos "não são apenas uma tradução do que pode ser lido para o que pode ser visto. Eles nos ajudam a entender, criar e experimentar a nossa realidade. Eles revelam o oculto, explicam o complexo e iluminam o obscuro". Numa definição menos poetizada, Módolo e Gouveia Júnior (2007) dizem que um dos principais objetivos dos infográficos seria mostrar a notícia em lugar de somente falar sobre ela. Ambas as definições de infográfico confluem para a ideia da multimodalidade, a integração entre os modos semióticos, principalmente elementos imagéticos e escritos, havendo uma orquestração de sentidos nessa integração.

Quanto aos usos do infográfico, Ribeiro (2016) explica que este é muito utilizado em revistas e jornais impressos e digitais e na televisão, nas previsões de tempo, nas explicações e nas demonstrações de fatos, causas, efeitos, trajetórias, entre outros aspectos. Isso acontece em virtude de o infográfico apresentar as informações de forma sucinta e "atraente". Sobre o letramento multimodal crítico, concordamos com Ribeiro (2016) quando a autora defende que um trabalho pedagógico em leitura e compreensão dos elementos visuais de um infográfico ainda precisa ser melhor desenvolvido nas escolas brasileiras. Como, no infográfico, existem alguns elementos composicionais como ilustrações, linhas, quadro, mapa, entre outros aspectos, pensamos que a Gramática do Design Visual de Kress e van Leeuwen (2006) será capaz de servir como aporte teórico para uma análise semiótica multimodal do infográfico "Panorama das favelas em Fortaleza".

\section{Análise do infográfico "Panorama das favelas em Fortaleza"}

O infográfico "Panorama das favelas em Fortaleza" foi publicado no site do jornal Tribuna do Ceará, um portal de notícias muito conhecido no Ceará e que pertence ao Sistema Jangadeiro de Comunicação. ${ }^{7}$ Em relação ao contexto sócio-histórico desse infográfico, percebemos que o portal ${ }^{8}$ fez uma

\footnotetext{
${ }^{7}$ O Sistema Jangadeiro de Comunicação é um conglomerado de mídia brasileiro com sede em Fortaleza, no Ceará. Ele concentra importantes veículos de comunicação na TV, no rádio e na internet.

${ }^{8} \mathrm{O}$ corpo editorial dessa matéria jornalística sobre a favela do Pirambu foi composta por:
} 
homenagem ao bairro Pirambu, localizado na área litorânea da zona oeste da cidade de Fortaleza. O referido bairro é considerado como a maior favela do Ceará e a sétima maior do Brasil, conforme informações do Portal Tribuna do Ceará. No entanto, o portal teve a intenção de mostrar o lado "bom" da favela, dando protagonismo ao bairro por meio da matéria jornalística "Pirambu em: meu nome é favela - ações que transformam" (LIMA, 2015), o que possibilitou dar relevância às ações sociais, às atividades comerciais e à rotina de pessoas humildes e dignas do referido bairro. Entre as imagens dessa matéria jornalística, encontra-se o infográfico analisado neste artigo. Vale ressaltar que o termo "favela" carrega um estigma, por isso o Instituto Brasileiro de Geografia e Estatística (IBGE) passou a classificar os diversos tipos de assentamentos irregulares existentes no país (favelas, invasões, baixadas e comunidades) como aglomerados subnormais no Censo Demográfico de 2010. Vale ressaltar que, embora utilize os dados do IBGE, a equipe editorial da reportagem do jornal virtual optou por manter a nomenclatura "favela" ao construir o infográfico (Figura 1):

FIGURA 1 - Infográfico "Panorama das favelas em Fortaleza"

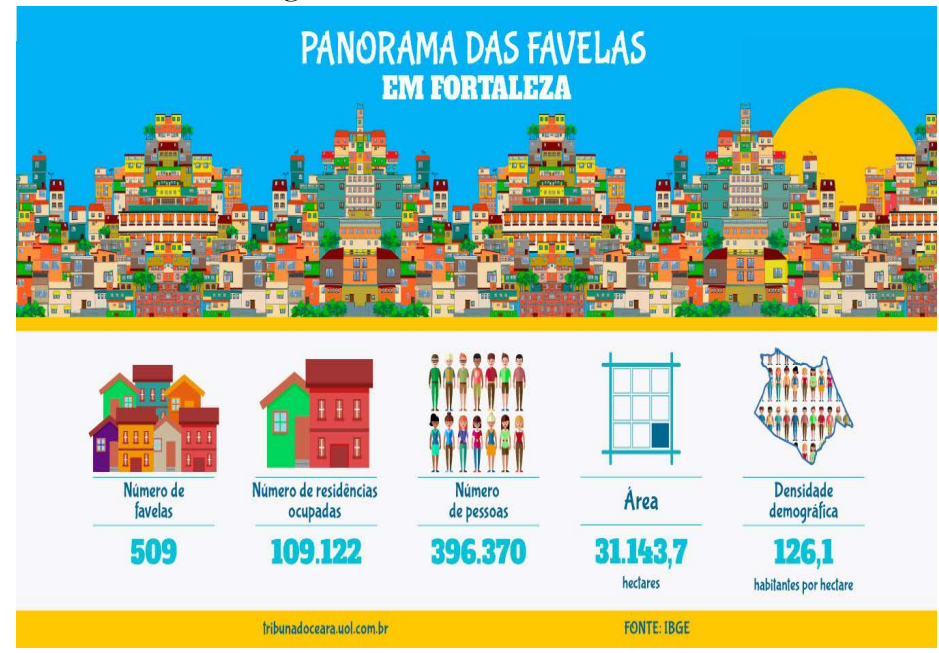

Fonte: Portal Tribuna do Ceará (LIMA, 2015)

na produção e edição, Felipe Lima; na reportagem, Felipe Lima, Rosana Romão e Roberta Tavares; e na infografia, Tiago Leite. Essa matéria foi publicada em 30 de junho de 2015 no site do jornal Tribuna do Ceará. 
Iniciamos esta análise pela metafunção representacional, pela qual podemos classificar a imagem presente no infográfico como conceitual, uma vez que a cidade de Fortaleza-CE está sendo mostrada em sua "essência" como se fosse um participante representado, abrangendo a sua plenitude urbana e de periferia. $O$ foco do infográfico nos parece ser pôr em evidência os atributos da cidade, no que tange às favelas, bem como há ausência de um plano de fundo e presença de uma disposição das informações por meio de categorias analíticas. Além disso, as favelas da capital cearense estão sendo mostradas, neste infográfico, a partir de aspectos estatísticos, provenientes do IBGE como: número de favelas, número de residências ocupadas, número de pessoas, área e densidade demográfica. Cada um desses aspectos também está sendo apresentado de forma conceitual já que não há um evento narrativo em nenhum deles, até os participantes representados (as pessoas) mostrados nos aspectos "número de pessoas" e "densidade demográfica” estão de forma estática e, apesar de terem olhos, boca e nariz muito pequenos, estes não podem ser considerados vetores em virtude do tamanho minúsculo e quase invisível. No entanto, a imagem representa os referidos participantes mostrando a diversidade étnica (cores diferentes), racial (cor e cabelo) e de gênero social (mulheres e homens) das favelas fortalezenses. Nos elementos "números de favelas" e "número de residências ocupadas", as casas se configuram como participantes representados de forma simbólica.

Classificamos a estrutura do infográfico como conceitual simbólica, uma vez que a parte de cima mostra um recorte, mesmo que idealizado, das favelas de Fortaleza, configurando-se como um "portador" cujos “atributos" ou informações extras são oriundos da pesquisa do IBGE e estão expostas na parte de baixo do infográfico. Esclarecemos que as imagens referentes ao número de favelas, ao número de residências ocupadas e ao número de pessoas são conceituais classificacionais, pois fazem parte de uma classificação hierárquica superior e mais abrangente evidenciada pelo elemento escrito localizado abaixo das três imagens mencionadas. Já a penúltima imagem parece ser analítica por representar um quadrado ou área de terra mostrando uma relação de parte e todo, em que a parte colorida de azul representa a quantidade de área ocupada pelas favelas (no caso, 1/9) e o quadrado maior a área de toda a capital cearense. A última imagem também pode ser considerada conceitual classificacional, já que há o esboço do mapa de Fortaleza representando a área total e os habitantes preenchendo 
e ocupando essa área como fragmentos da densidade demográfica total da cidade.

Em relação à metafunção interativa, de acordo com a GDV, percebemos que os modos pelos quais a imagem estabelece relações com o leitor-olhante não se concretizam por meio de vetores, já que não há participantes representados humanos. Entretanto, consideramos que, na parte de cima do infográfico, a imagem da favela está recebendo protagonismo visual que a torna participante representado, sendo exposta como item de oferta e objeto de contemplação, de forma impessoal. Pensamos também que o uso das cores na imagem da favela pode também servir para instigar a dimensão afetiva (BARBOSA, 2017; CALLOW, 2008), que, ao nosso ver, tem relação com a metafunção interativa a partir do momento que faz com que o leitor-olhante "simpatize" com a imagem da favela ou "antipatize" no caso de pessoas que veem a favela de forma não idealizada e mais real. Além disso, a parte de cima do infográfico está em plano aberto e em longa distância, o que propicia um enquadramento de distância, imprimindo um caráter de impessoalidade. O mesmo ocorre também com as imagens da parte de baixo do infográfico. Dessa forma, pela GDV, predomina essa impessoalidade em virtude do enquadramento, porém defendemos que o uso das cores pode amenizar ou até "quebrar" esse distanciamento. Além disso, o fato de a imagem estar em ângulo frontal traz a possibilidade de criar um envolvimento com o leitor-olhante. No que concerne às imagens da parte de baixo, todas as cinco apresentam ângulo frontal associado ao uso de cores, exceto a imagem referente à área, que usufrui apenas da cor azul e não possibilita tanto envolvimento com o leitorolhante por meio das cores.

Quanto à modalidade, acreditamos que a imagem da parte de cima do infográfico pode ser classificada como sensorial devido à maneira em que foi retratada a favela com o intuito de produzir um impacto sensorial ou efeito que transcende o real, evocando sentimentos subjetivos no leitorolhante ou até com a finalidade de quebrar o "estigma" ou "carga negativa" existente em relação à favela com o uso das cores nas casas e dos elementos composicionais "romantizados" como o amarelo do sol e o azul do céu, entre outros. Já na parte de baixo do infográfico, a imagem relativa à área apresenta uma modalidade tecnológica e/ou científica, pois a verdade visual que o produtor tenta passar se encontra na representação da fração da área ocupada por favelas. Ademais, a modalidade científica se faz presente 
também nos elementos escritos das cinco composições multimodais da parte de baixo do infográfico, já que passam a veracidade das pesquisas estatísticas. Quanto à metafunção composicional, percebemos que, no que tange ao valor de informação, seguindo os preceitos da GDV, a relação dado e novo não se enquadra nesse infográfico, já que todos os elementos estatísticos são considerados novas informações, visto que foram fruto de pesquisas estatísticas do IBGE e que se tornaram públicas para a sociedade, de um modo geral, somente em 2015. No entanto, isso não descarta a possibilidade de que as informações "número de favelas, número de residências ocupadas, número de pessoas, área e densidade demográfica" não sejam conhecidas, ao menos de forma empírica, pelos membros da favela. Existe, nesse infográfico, uma divisão clara sinalizada pela linha amarela que divide a imagem ao meio. Entre a metade superior e a outra metade inferior, de acordo com a teoria de Kress e van Leeuwen (2006), percebemos que a favela exposta na parte de cima do infográfico se configura como elemento ideal, pois apresenta a favela com muita beleza e estrutura arquitetônica "organizada" e "adequada" para a população mais carente, escamoteando a realidade da favela, que, conforme Cavallieri (2009, p. 26), possui os seguintes aspectos:

precariedade da organização espacial (ruas estreitas, de traçados irregulares, não carroçais, dificuldades para circulação de pedestres; dificuldade de acesso a partir do entorno urbanizado e circulação interna precária; precariedade de infraestrutura (redes de água e esgotos não oficiais ou inexistentes; coleta indireta de lixo; inexistência de varredura das vias e limpeza dos cursos d'água, drenagem inexistente ou insuficiente); precariedade e/ou dificuldade de acesso a equipamentos coletivos (escolas, creches, centros sociais, postos de saúde, praças e quadras de esporte); precariedade das construções residenciais e comerciais (materiais construtivos, insolação, aeração, falta de telhado, revestimento externo); falta de regularização fundiária (títulos informais de propriedade); ausência de regularização urbanística (normas e fiscalização sobre o uso e ocupação do solo e sobre posturas, alvarás de funcionamentos de estabelecimentos, denominação oficial de logradouros, habite-se das edificações etc.); irregularidade fiscal (imóveis não constam nos cadastros imobiliários, não são tributados, não pagam tarifas pela prestação de serviços públicos); imóveis habitados, predominantemente, por população de baixa renda. 
Por isso, avaliamos que os elementos reais estão na metade inferior em virtude de apresentarem dados obtidos pelo IBGE, uma instituição renomada e reconhecida nacionalmente por fazer pesquisas idôneas e éticas. Identificamos nos significados composicionais as cores vivas e vibrantes, os elementos repetidos e sobrepostos numa descrição idealizada e organizada do participante representado ("Favelas de Fortaleza"), como um local que não possui as características apontadas por Cavallieri (2009). As informações reais (os dados estatísticos) estão em destaque na cor azul através dos algarismos numéricos que também estão em saliência na imagem em relação ao plano de fundo branco. Conforme Kress e van Leeuwen (2002), a cor azul passa veracidade e conhecimento, além de passar tranquilidade (CALLOW, 2013) a fim de não "assustar" os leitores-olhantes com os números elevados.

Analisamos também a presença das cores repetidas na imagem: azul (no céu e nos números) e amarelo (no sol e na linha horizontal que divide a imagem e aparece na barra inferior), os quais estão como elementos simbólicos que conectam as duas partes criando um efeito coesivo para produzir sentido. Tal indicação aponta para a denominada estruturação forte, já que há contraste de cores (azul, amarelo e branco) e formas salientes ("minifavela", casas habitadas, conjunto de pessoas, quadrado subdividido, mapa de Fortaleza com pessoas dentro, que se destacam sobre o fundo branco da parte de baixo), bem como há um espaço branco (plano de fundo) entre esses elementos estabelecendo uma diferenciação entre os elementos imagéticos da parte de baixo do infográfico. Na parte de cima, identificamos a representação imagética da favela como elemento saliente em virtude do uso misturado de cores fortes que aparecem em toda imagem. Para Barbosa (2017), é possível inferir que, no trabalho semiótico de construção de sentidos, as cores desempenharam um papel fundamental ao atrair e envolver os participantes interativos (leitores-olhantes) no processo de leitura e interpretação de composições multimodais. Por isso, destacamos que a mesma cartela de cores que está presente na imagem superior também está evidente e repetida nas imagens menores que estão relacionadas aos números apresentados, bem como há saliência na faixa amarela localizada na parte inferior do infográfico, destacando os elementos escritos referentes ao site do Portal Tribuna do Ceará (LIMA, 2015) e à fonte das informações estatísticas, o IBGE, como componentes reais. Essa citada redundância no uso das cores é apontada na GDV como um recurso de conexão e é denominada como rima visual, referindo-se à "repetição de cores e formas 
em diferentes elementos da composição"" (KRESS; VAN LEEUWEN, 2006, p. 204, tradução nossa).

Diante desta breve análise, concordamos com Barbosa (2017) quando a autora advoga que as categorias da Gramática do Design Visual de Kress e van Leeuwen (2006) são aplicáveis à compreensão das composições multimodais e servem para guiar a leitura e direcionar o olhar do leitor-olhante, especialmente para os elementos imagéticos, porém a referida gramática não apresenta "fórmulas" nas quais todo texto pode ser enquadrado. Como vimos nesta análise, na metafunção composicional, os elementos dados e novos não foram expostos no infográfico.

Partindo para um contexto escolar, com a finalidade de desenvolver o letramento multimodal crítico ${ }^{10}$ de estudantes de Ensino Médio, por exemplo, é necessário que o professor instigue a reflexão a partir do infográfico "Panorama das favelas em Fortaleza" sobre o discurso jornalístico do Portal Tribuna do Ceará (LIMA, 2015), que traz uma tentativa de reduzir e amenizar o estigma de periculosidade e pobreza das favelas, mostrando aspectos positivos sobre viver na favela do Pirambu, bem como serve para promover uma certa "acomodação" dos fortalezenses (sejam ou não moradores das favelas) para não reivindicar por melhorias sociais na comunidade em que vivem.

Com base no Show me framework de Callow (2008), acreditamos que o professor pode explorar a dimensão afetiva indagando sobre quais sentimentos e primeiras impressões em relação ao infográfico os estudantes constroem; se eles gostam ou não do infográfico e por quê; no caso de discentes de bairros pobres, se eles se identificam com essa imagem de favela presente no infográfico. $\mathrm{Na}$ dimensão composicional, o professor pode perguntar sobre os pontos de saliência, os vetores, o uso das cores, as ações, os símbolos, a proximidade ou o distanciamento (por meio dos ângulos), entre outros aspectos concernentes à GDV. Na dimensão crítica, o docente deve indagar sobre as ideologias e os discursos presentes no infográfico a fim de que os estudantes identifiquem as intencionalidades existentes por parte dos produtores do infográfico. Depois disso, o professor deve permitir

\footnotetext{
${ }^{9}$ No original: "repetition of colours and shapes in different elements of the composition" (KRESS; VAN LEEUWEN, 2006, p. 204).

${ }^{10}$ Ressaltamos que o letramento multimodal crítico é composto por ações como "selecionar, combinar e analisar de maneira situada e crítica os múltiplos recursos semióticos" (PREDEBOM, 2015, p. 48).
} 
que o aluno concorde ou discorde com o que está sendo representado no infográfico, com a finalidade de possibilitar um posicionamento crítico e um empoderamento social por parte do alunato.

Além disso, o professor, a partir do Show me framework de Callow (2008), pode explorar as estratégias multimodais em que os dados do IBGE foram expostos pelo jornal digital de forma criativa e, ao mesmo tempo, utópica, escamoteando a difícil realidade arquitetônica, urbanística e social das favelas da capital cearense. Pensamos também que o docente pode instigar os estudantes a não reproduzirem um discurso preconceituoso em relação à favela, mas devendo perceber estratégias de como reagir sociopoliticamente contra situações de exclusão e desigualdade social.

\section{Considerações finais}

Este artigo pretendeu mostrar que as imagens apresentam nuances que colaboram diretamente na construção de sentidos da composição multimodal do infográfico "Panorama das favelas em Fortaleza", pois, conforme a Gramática do Design Visual, as imagens apresentaram uma representação conceitual simbólica com teor de idealização da favela, principalmente na parte de cima do infográfico em questão. A estrutura de cada elemento visual do infográfico (uma imagem maior na metade de cima e outras cinco composições imagéticas na parte de baixo) tentou "amenizar" a dureza das informações escritas e numéricas, especialmente pelo uso da cor azul, mas, ao mesmo tempo, elas aparecem salientes em um plano de fundo branco. A interação entre as imagens do infográfico e o leitor-olhante ocorre de uma forma impessoal pelo enquadramento, mas há também uma tênue proximidade por meio do uso das cores. Dessa forma, parece-nos que os elementos representacionais, interativos e composicionais da GDV são usados pelos produtores do infográfico, no caso o Portal Tribuna do Ceará (LIMA, 2015), para mostrar de forma criativa e amena os dados estatísticos do IBGE sobre um problema social, que foi integrado ao texto escrito em uma matéria jornalística do mencionado portal com o objetivo de amenizar o estigma da violência e da pobreza da favela do Pirambu (também considerado bairro em virtude da sua dimensão geográfica).

Em sala de aula, sugerimos que os professores de história, geografia e língua portuguesa atuem de forma paralela com os alunos, mostrando aspectos do discurso escrito e imagético, podendo empregar a teoria da Gramática do Design Visual (KRESS; VAN LEEUWEN, 2006) e do Show 
me framework (CALLOW, 2008), a fim de possibilitar um empoderamento social e uma posição crítica em relação às intencionalidades dos produtores do infográfico, às ideologias que perpassam os discursos midiáticos e institucionais, às transformações sócio-históricas que o Ceará e o bairro Pirambu passaram no último século, às estratégias de re(con)textualização do infográfico, que (re)constrói significados quando integrado a outros elementos escritos ou imagéticos, entre outras possibilidades.

Diante do infográfico "Panorama das favelas em Fortaleza" e das múltiplas possibilidades didáticas de se trabalhar o infográfico em sala de aula, transborda-nos o desejo de que mais professores possam proporcionar o desenvolvimento do letramento multimodal crítico a fim de gerar sujeitos mais atuantes e menos manipuláveis ideologicamente na sociedade atual.

\section{Referências}

ASSUNÇÃO, F. N. Análise multimodal de infográfico. In: JORNADA NACIONAL DO GRUPO DE ESTUDOS LINGUÍSTICOS DO NORDESTE, 24., 2012, Natal. Anais... Natal: EDUFRN, 2012.

BARBOSA, V. S. Multimodalidade e letramento visual: uma proposta de intervenção pedagógica para integrar as habilidades de ler e ver no processo de ensino e aprendizagem de Inglês como Língua Estrangeira. 2017. 414 f. Tese (Doutorado em Linguística Aplicada) - Centro de Humanidades, Universidade Estadual do Ceará, Fortaleza, 2017.

CALLOW, J. Show me: principles for assessing students' visual literacy. The Reading Teacher, Newark, v. 6, n. 18, p. 616-626, 2008. Doi.org/10.1598/RT.61.8.3

CALLOW, J. The rules of visual engagement: images as tools for learning. Screen Education, Saint Kilda, n. 65, p. 72-79, 2012. Disponível em: <https://goo.gl/ UkZytY>. Acesso em: 2 jul. 2017.

CALLOW, J. The shape of text to come: how image and text work. Newtown: PETAA, 2013.

CATTO, N. R. A relação entre o letramento multimodal e os multiletramentos na literatura contemporânea: alinhamentos e distanciamentos. Fórum Linguístico, Florianópolis, v. 10, n. 2, p. 157-163, 2013. Doi.org/10.5007/19848412.2013v10n2p157

CAVALLIERI, F. Favelas no Rio: a importância da informação para as políticas públicas. In: SILVA, J. S. et al. (Org.). O que é favela, afinal? Rio de Janeiro: Observatório de Favelas do Rio de Janeiro, 2009. p. 24-29. Disponível em: <https://goo.gl/NS15Mv>. Acesso em: 6 jul. 2017. 
FERNANDES, J. D. C.; ALMEIDA, D. B. L. Revisitando a gramática visual nos cartazes de guerra. In: ALMEIDA, D. B. L. (Org.). Perspectivas em análise visual: do fotojornalismo ao blog. João Pessoa: UFPB, 2008. p. 11-31.

FRANCHI, F. The limits of infographics. Francesco Franchi, Milan, 2010. Disponível em: <https://goo.gl/oxCqEP>. Acesso em: 5 jul. 2017.

HALLIDAY, M. A. K. Language as social semiotic: the social interpretation of language and meaning. London: Edward Arnold, 1978.

HODGE, R.; KRESS, G. Social semiotics. In: . Social Semiotics. Ithaca: Cornell University, 1988. p. 1-12.

KRESS, G. et al. Multimodality. In: . Multimodal teaching and learning: the rhetorics of the science classroom. London: Continuum, 2001. p. 42-59.

KRESS, G.; VAN LEEUWEN, T. Colour as a semiotic mode: notes for a grammar of colour. Visual Communication, London, v. 1, n. 3, p. 343-368, 2002. Doi. org/10.1177/147035720200100306

KRESS, G.; VAN LEEUWEN, T. Multimodal discourse: the modes and media of contemporary communication. London: Arnold, 2001.

KRESS, G.; VAN LEEUWEN, T. Reading images: the grammar of visual design. London: Routledge, 2006.

LIMA, F. Pirambu em: meu nome é favela: ações que transformam. Tribuna do Ceará, Fortaleza, 30 jun. 2015. Disponível em: <https://goo.gl/BmUVKX>. Acesso em: 5 jul. 2017.

MIRZOEFF, N. Introducción a la cultura visual. Barcelona: Paidós, 2003.

MÓDOLO, C. M.; GOUVEIA JÚNIOR, A. Estudo quantitativo dos infográficos publicados na revista Superinteressante nos anos de 1987 a 2005. In: CONGRESSO BRASILEIRO DE CIÊNCIAS DA COMUNICAÇÃO, 30., 2007, Santos. Anais... Santos: Unisanta, 2007. p. 1-14.

NASCIMENTO, R. G; BEZERRA, F. A. S.; HEBERLE, V. M. Multiletramentos: iniciação à análise de imagens. Linguagem \& Ensino, Pelotas, v. 14, n. 2, p. 529-552, 2011.

NEW LONDON GROUP. A pedagogy of multiliteracies: designing social futures. In: COPE, B.; KALANTZIS, M. (Org.). Multiliteracies: literacy learning and the design of social futures. New York: Routledge, 2006. p. 9-37.

PAIVA, F. A. O gênero textual infográfico: leitura de um gênero textual multimodal por alunos da 1a série do Ensino Médio. Revista @@el em (dis-)curso, São Paulo, v. 3, n. 1, 2011. p. 87-101. 
PINHEIRO, M. S. Investigando o letramento multimodal crítico de alunos de espanbol do Ensino Médio de uma escola pública de Fortaleza-CE. 2016.316 f. Dissertação (Mestrado em Linguística Aplicada) - Centro de Humanidades, Universidade Estadual do Ceará, Fortaleza, 2016.

PREDEBOM, N. R. C. Do entretenimento à crítica: letramento multimodal crítico no livro didático de inglês com base em gêneros dos quadrinhos. 2015. $241 \mathrm{f}$. Tese (Doutorado em Letras) - Centro de Artes e Letras, Universidade Federal de Santa Maria, Santa Maria, 2015.

RIBEIRO, A. E. Textos multimodais: leitura e produção. São Paulo: Parábola, 2016.

SILVA, M. Z. V. da. O letramento multimodal crítico no Ensino Fundamental: investigando a relação entre a abordagem do livro didático de língua inglesa e a prática docente. 2016. 327 f. Tese (Doutorado em Linguística Aplicada) - Centro de Humanidades, Universidade Estadual do Ceará, Fortaleza, 2016.

WALSH, M. Multimodal literacy: what does it mean for classroom practice? Australian Journal of Language and Literacy, Norwood, v. 3, n. 3, p. 211-239, 2010.

Data de submissão: 27/12/2017. Data de aprovação: 24/05/2018. 